\title{
Industrial and agricultural ammonia point sources exposed
}

\author{
Martin Van Damme ${ }^{1,3 *}$, Lieven Clarisse ${ }^{1,3 *}$, Simon Whitburn ${ }^{1}$, Juliette Hadji-Lazaro ${ }^{2}$, Daniel Hurtmans ${ }^{1}$, Cathy Clerbaux ${ }^{1,2} \&$ \\ Pierre-François Coheur ${ }^{1}$
}

Through its important role in the formation of particulate matter, atmospheric ammonia affects air quality and has implications for human health and life expectancy ${ }^{1,2}$. Excess ammonia in the environment also contributes to the acidification and eutrophication of ecosystem $\mathrm{s}^{3-5}$ and to climate change ${ }^{6}$. Anthropogenic emissions dominate natural ones and mostly originate from agricultural, domestic and industrial activities ${ }^{7}$. However, the total ammonia budget and the attribution of emissions to specific sources remain highly uncertain across different spatial scales ${ }^{7-9}$. Here we identify, categorize and quantify the world's ammonia emission hotspots using a high-resolution map of atmospheric ammonia obtained from almost a decade of daily IASI satellite observations. We report 248 hotspots with diameters smaller than 50 kilometres, which we associate with either a single point source or a cluster of agricultural and industrial point sources-with the exception of one hotspot, which can be traced back to a natural source. The state-of-the-art EDGAR emission inventory ${ }^{10}$ mostly agrees with satellitederived emission fluxes within a factor of three for larger regions. However, it does not adequately represent the majority of point sources that we identified and underestimates the emissions of two-thirds of them by at least one order of magnitude. Industrial emitters in particular are often found to be displaced or missing. Our results suggest that it is necessary to completely revisit the emission inventories of anthropogenic ammonia sources and to account for the rapid evolution of such sources over time. This will lead to better health and environmental impact assessments of atmospheric ammonia and the implementation of suitable nitrogen management strategies.

Considerable effort goes into establishing spatially and temporally resolved ammonia $\left(\mathrm{NH}_{3}\right)$ bottom-up emission inventories, as these are critical drivers of models that are used to assess $\mathrm{NH}_{3}$ distributions and impacts on the environment. Bottom-up inventories are built from activity data coupled with estimated emission factors. The correctness of these input data is their Achilles' heel, as activity data can be absent or outdated and estimated emission factors are based on specific case studies and may not be representative of either local or global conditions ${ }^{11,12}$. When they are available, global measured atmospheric distributions of trace gas concentrations allow us to retrieve source emissions. In the past few years, satellite sounders have offered (bi) daily global $\mathrm{NH}_{3}$ measurements ${ }^{13-17}$, which have a huge potential to improve our knowledge of the $\mathrm{NH}_{3}$ emission budget ${ }^{18}$. The first global distributions ${ }^{13}$ and inverse modelling efforts ${ }^{19}$ have confirmed the correctness of the location of the large source regions in the inventories, but have also revealed likely underestimates in the magnitude of their emissions, especially in the Northern Hemisphere. A regional study ${ }^{20}$ has highlighted the advantage of averaging data to reveal smaller, localized $\mathrm{NH}_{3}$ point sources, for which there is a single discernible source of pollution. Here we capitalize on nine years of IASI (Infrared Atmospheric Sounding Interferometer) measurements to produce a global distribution of $\mathrm{NH}_{3}$ at hyperfine resolution to identify, categorize and quantify the world's main $\mathrm{NH}_{3}$ emission hotspots, down to the point source, and to benchmark the state-of-the-art emission inventory EDGAR (Emissions Database for Global Atmospheric Research) v4.3.10.

Using an oversampling approach that exploits the variable spatial extent and coverage of the satellite pixels (Methods), a nine-year global average of daily cloud-free IASI observations was obtained. The global map is shown in Fig. 1a, along with three zooms over South and North America (Fig. 1b), Europe, northern Africa and Middle East (Fig. 1c), and Asia (Fig. 1d). We note that the global map shown in Fig. 1a differs from the first reported global distribution obtained from one year of IASI measurements ${ }^{13}$ in several aspects (in addition to the different periods considered for averaging) owing to major improvements in the retrieval algorithm, which takes into account the variable measurement sensitivity between regions ${ }^{15,21}$. We analysed the map and isolated and identified 248 hotspot locations (Methods; Extended Data Figs. 1, 4; Supplementary Information). These consist of areas of limited geographical extent $(<50 \mathrm{~km})$ that exhibit a large local $\mathrm{NH}_{3}$ enhancement and typically contain one or more closely located point sources. Hotspots were included in the list only if they could be identified unambiguously on the basis of satellite data alone (Methods). 178 regions with enhanced $\mathrm{NH}_{3}$ columns, but with no clear, well-defined hotspots, were also inventoried (Extended Data Fig. 1; Supplementary Information). These source regions correspond to, for example, crop fields, biomass-burning areas, mixed sources, larger hotspots or several neighbouring ones. The largest regions are the Indo-Gangetic Plain, North China Plain and the biomass-burning-dominated West Africa and Amazonia. Regions dominated by biomass burning were mostly excluded from this study because identification of hotspots in such regions is very difficult and because we compare our results with a static-emission inventory that does not include emissions from fires (Methods). The hotspots were further analysed to determine the predominant emitter.

By combining information from visible imagery, publicly available inventories ${ }^{22,23}$ and online sources (Methods), the identified hotspots could be classified in three classes: agricultural, industrial and natural. Illustrative examples are shown in Fig. 2 and detailed figures are provided in the Supplementary Information.

The 83 hotspots in the agricultural class were consistently found to be associated with intensive animal farming, either in the form of open feedlots or within enclosed housings, as identified by aerial photographs. For instance, the localized $\mathrm{NH}_{3}$ maximum found over Eckley-Yuma (Colorado, USA; Fig. 2a) can be seen to coincide spatially with two large cattle feedlots. These are situated in a large agricultural region dominated by centre-pivot-irrigated fields, but with much lower average $\mathrm{NH}_{3}$ concentrations. Bakersfield and Tulare (California, USA) and Torreón (Mexico) are other examples of feedlot-dominated hotspots within a much larger intensive-agriculture region. Milford (Utah, USA), which is located in an otherwise remote mountainous area, is the home of massive pig farms, with associated open waste pits (Fig. 2b). 

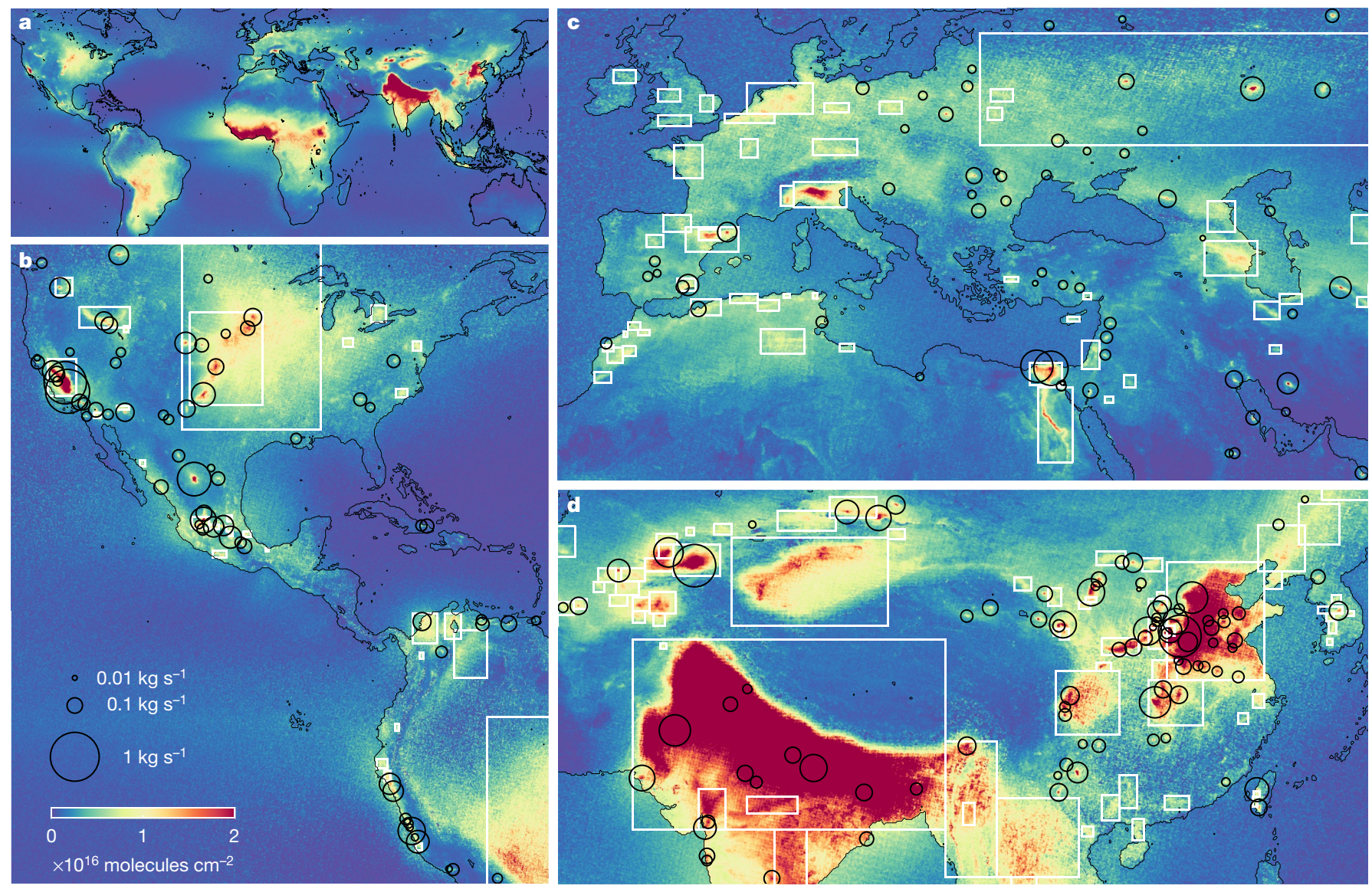

Fig. 1 | IASI nine-year oversampled average, hotspots and source regions. a, Nine-year global IASI average $\mathrm{NH}_{3}$ distribution (in molecules per square centimetre). b-d, Zoom-ins over South and North America (b), Europe, northern Africa and the Middle East (c) and Asia (d). Hotspots are indicated with black circles; their size quantifies the satellite-based emission fluxes (in kilograms per second). Source regions are delineated in white. The largest average $\mathrm{NH}_{3}$ column is found over the Indus Valley (Pakistan) with a value of $1.1 \times 10^{17}$ molecules $\mathrm{cm}^{-2}$.
$\mathrm{NH}_{3}$ emissions associated with poultry housings were also identified, for example, in the Alto Laran district (Peru; Fig. 2c) or in Basmakci (Turkey), a centre of egg production ${ }^{24}$

The second class (158 hotspots in total), that of industrial emitters, was in majority traced back to plants producing $\mathrm{NH}_{3}$-based fertilizer, for which over 130 sites were found. Well-isolated examples include the plants in Marvdasht (Iran; Fig. 2d), Pingsongxiang (Shanxi, China), Cherkasy (Ukraine), Sur Industrial Estate (Oman) and Beech Island (South Carolina, USA). Fertilizer plants are often found to be geographically close to their (agricultural) distribution market, such as the plants in the Ferghana Valley (Uzbekistan) and in the Nile Delta (Talkha and Abu Qir, Egypt). These industrial point sources clearly emerge in the nine-year IASI average, despite the already large background concentrations. Many fertilizer plants are also found near coal-related industries (coal mining, thermal power plants, coke production and other chemical coal industries). Secunda (South Africa) is an archetype of such a hotspot. In China, such examples are abundant; for instance, the large industry park in Shizuishan (Ningxia; Fig. 2e) or the intense hotspot over Zezhou-Gaoping (Shanxi). For these sites, fertilizer production is only part of the total industrial source. Other fainter industrial hotspots were found over nickel-cobalt mines (Moa and Nicaro, Cuba; Fig. 2f), soda-ash plants (Stuparei, Romania; Fig. 2g) and a complex of geothermal power plants (The Geysers, California, USA; Fig. $2 \mathrm{~h}$ ).

The third class includes natural emitters. Natural emissions from oceans, non-agricultural soils and plants represent a substantial part of the total atmospheric $\mathrm{NH}_{3}$ budget ${ }^{7}$. However, these sources are generally too diffuse to appear as hotspots in the satellite data. Of all the hotspots that were identified, only the one near Lake Natron (Tanzania) is likely to have a natural origin. This hotspot occurs over Natron's main mudflat and may be related to the decay of algae. It is, however, unclear why $\mathrm{NH}_{3}$ emissions are larger at Lake Natron than at other soda lakes with similar regularly exposed mudflats. Other known natural point sources include seal and seabird colonies and volcanoes ${ }^{25-27}$. Bird colonies are found in coastal areas and especially at high latitudes. In these areas, satellites are generally less effective as a detection and monitoring tool because of high turbulent mixing (which does not allow $\mathrm{NH}_{3}$ to build up), high cloud cover and low thermal contrast (Methods). Enhanced $\mathrm{NH}_{3}$ columns near some volcanoes were found to be associated with fires.

To assess the importance of the different point sources quantitatively, the nine-year-averaged emission fluxes were calculated for all hotspots and source regions using an inverse modelling approach (Methods). We compared these with the bottom-up emission inventory EDGAR (excluding biomass-burning regions, as detailed in Methods, Supplementary Information and Fig. 1). To test the validity of our approach, flux estimates from the identified source regions were first compared with EDGAR and are presented in Fig. 3 (diamonds). For $78 \%$ of the source regions, the fluxes agree within a factor of $3(89 \%$ within a factor of 5) and, importantly, when all regions are considered, no major bias is observed.

For the flux calculations of the hotspots, background concentrations were removed to isolate the contribution of the point sources within (Methods). The flux comparisons are presented in Fig. 3, for agricultural (circles) and industrial (triangles) sources. It is immediately clear that emissions from almost all identified hotspots are underestimated in EDGAR, irrespective of their class. Of the 241 industrial and agricultural hotspots, only $7 \%$ agree within a factor of 2 and only one-third within one order of magnitude. 77 hotspots have a nearby local maximum in the inventory and can therefore be considered to be known, albeit with a flux rate that is too low. Representative examples 

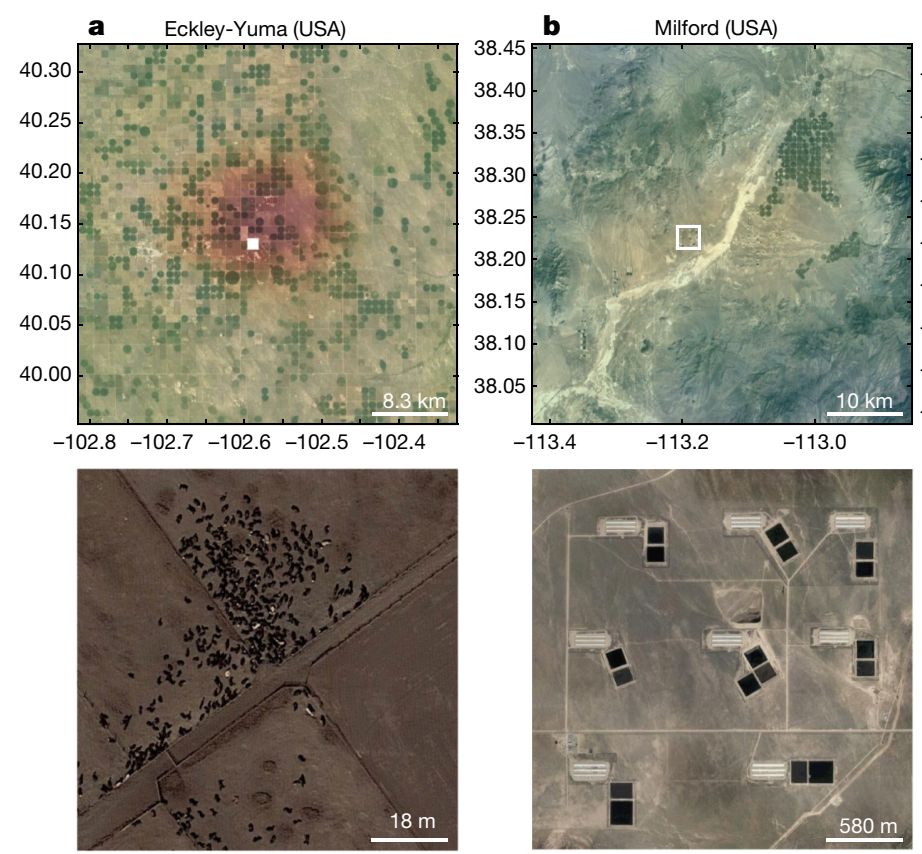

Cattle feedlot

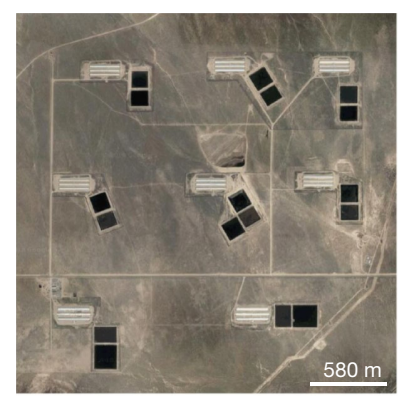

Pig farms
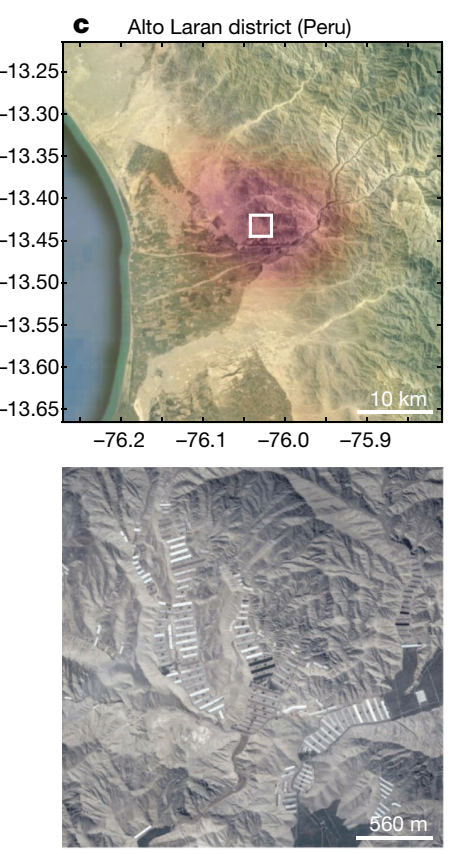

Poultry housing
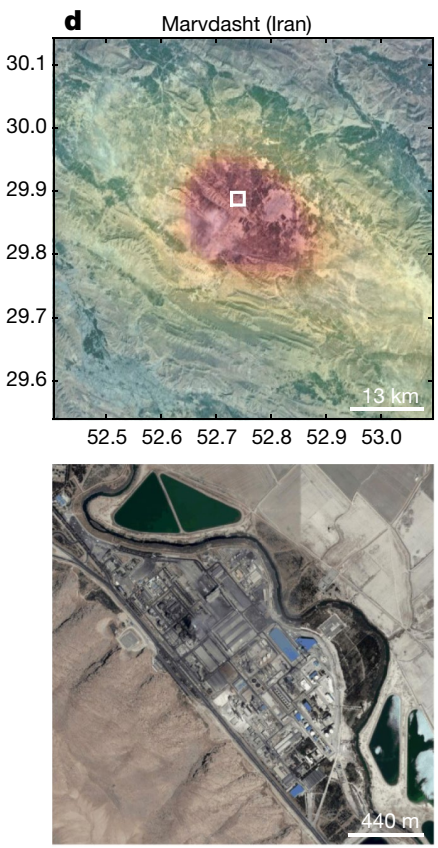

Fertilizer plant

\section{$\begin{array}{lllll}0.0 & 0.5 & 1.0 & 1.5 & 2.0\end{array}$}
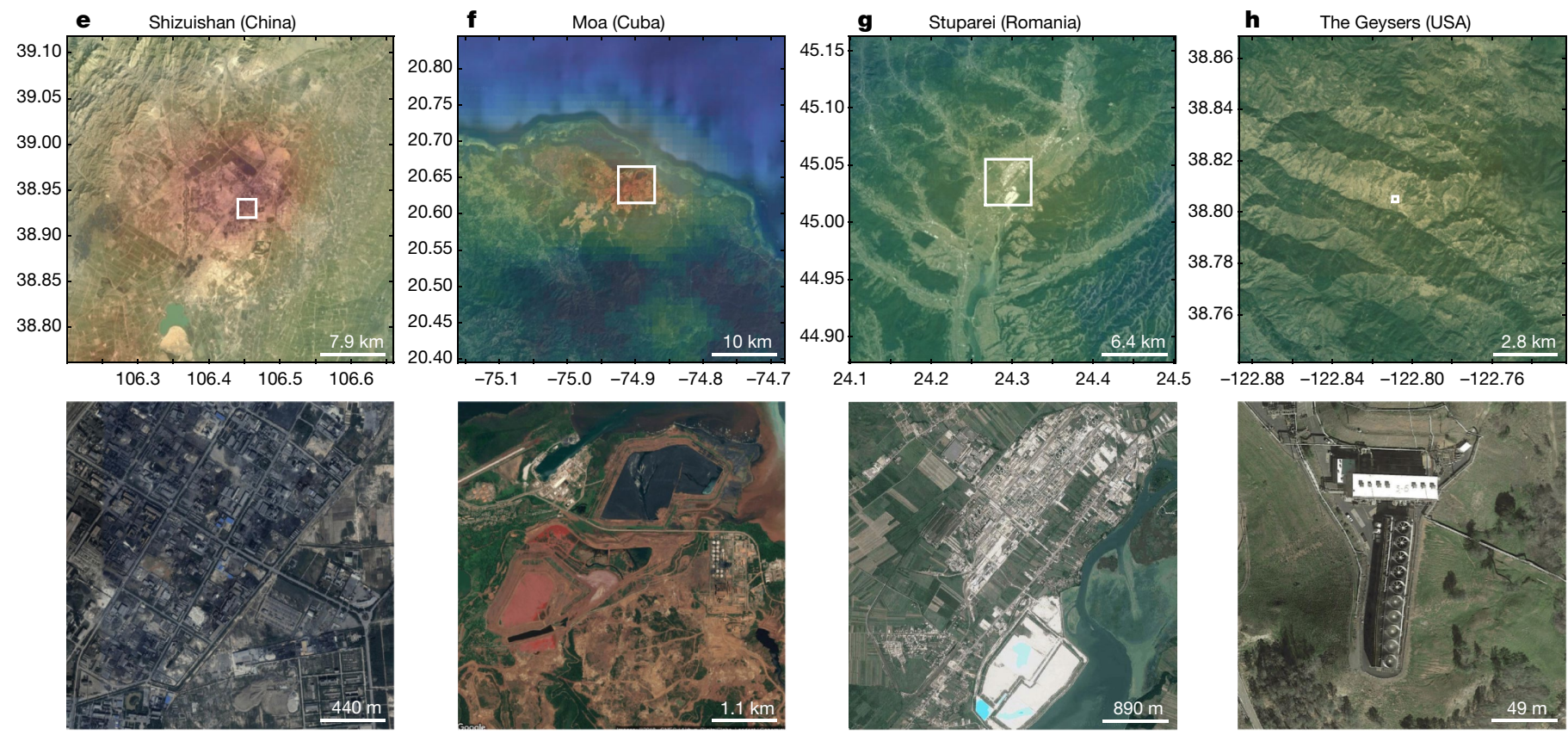

Nickel and cobalt mine/plant

Fertilizer and coal-related industries

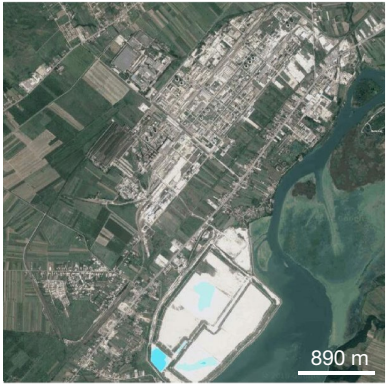

Soda-ash plant

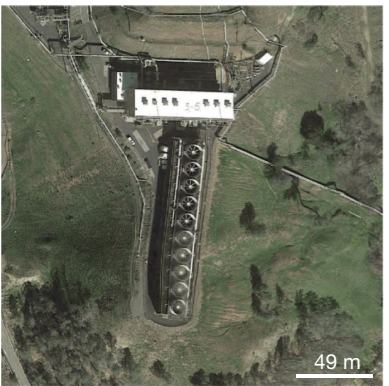

Geothermal power plant

Fig. 2 | Examples of industrial and agricultural point sources.

a-h, For each site, the top panels overlay $\mathrm{NH}_{3}$ total columns from the nine-year IASI average (in $10^{16}$ molecules $\mathrm{cm}^{-2}$ ) on visible imagery (the vertical and horizontal axes correspond to latitude and longitude, respectively; the location of each site is also indicated in Extended Data Fig. 1 and Supplementary Fig. 1). The bottom panels offer a close-up

shown in Fig. 3 include Sur Industrial Estate and Cherkasy for industry and Tulare and Torréon for agriculture. Many of the (industrial) point sources seem slightly displaced, by at least one EDGAR grid cell, from the identified hotspot centre, which corresponds to about $10 \mathrm{~km}$ (for example, Secunda and Beech Island). Some are so far away that they could not be included in the above count-notably the Marvdasht plant in Iran, which seems to be recorded in the inventory at a location over $20 \mathrm{~km}$ southwest from the actual place of emission. The other 164 hotspots do not represent a local maximum in EDGAR and are largely

view of the areas delineated in white. The colour scale ranges from 0 to $2 \times 10^{16}$ molecules $\mathrm{cm}^{-2}$ except for Shizuishan where it ranges from 0 to $3 \times 10^{16}$ molecules $\mathrm{cm}^{-2}$. The $\mathrm{NH}_{3}$ source is indicated under each aerial photograph. Map data from Google Earth, CNES/Airbus, DigitalGlobe and Landsat/Copernicus.

underestimated compared to IASI data. There is one agricultural site (Chino, California, USA) and 69 industrial sites that can be considered completely absent from the EDGAR inventory because their fluxes are at least two orders of magnitude lower than the measurement.

For most of the hotspots, it was possible to calculate yearly emission fluxes and observe their time evolution over the nine years of IASI measurements. It is noteworthy that the onset or the discontinuation of anthropogenic activity could be detected unambiguously (Fig. 4). Numerous new industrial point sources that emerged within the IASI 


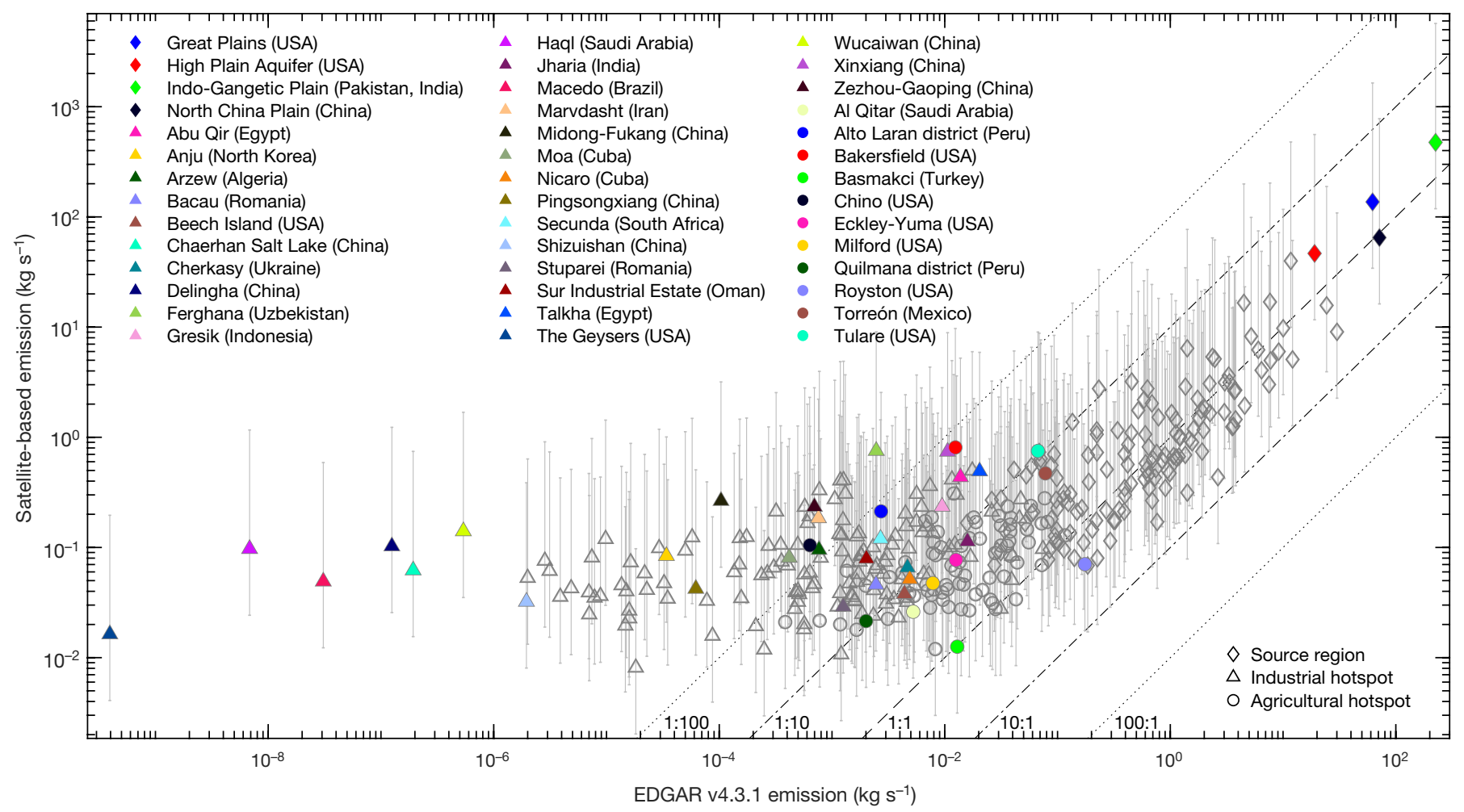

Fig. 3 Satellite-derived emission fluxes versus a bottom-up emission inventory. Satellite-based emission estimates (in kilograms per second) for industrial (triangles) and agricultural (circles) hotspots and source regions (diamonds), compared with the EDGAR v4.3.1 emission inventory. The dashed, dash-dotted and dotted black lines represent ratios of EDGAR emission to satellite-based emission of $1: 1,1: 10$ or $10: 1$, and $1: 100$ or

measurement period were found in this way, especially in Asia. $\mathrm{NH}_{3}$ is observed, for example, above Wucaiwan (Xinjiang, China) from 2012 onwards, which coincides with the establishment of a fertilizer factory. Industrial plant closures were also detected, for example, over Bacau (Romania) and Nicaro (Cuba) in 2013. Agriculture in transition was also identified, such as the rapid expansion of poultry farms in the central coastal regions of Peru (for instance, in the Alto Laran district).

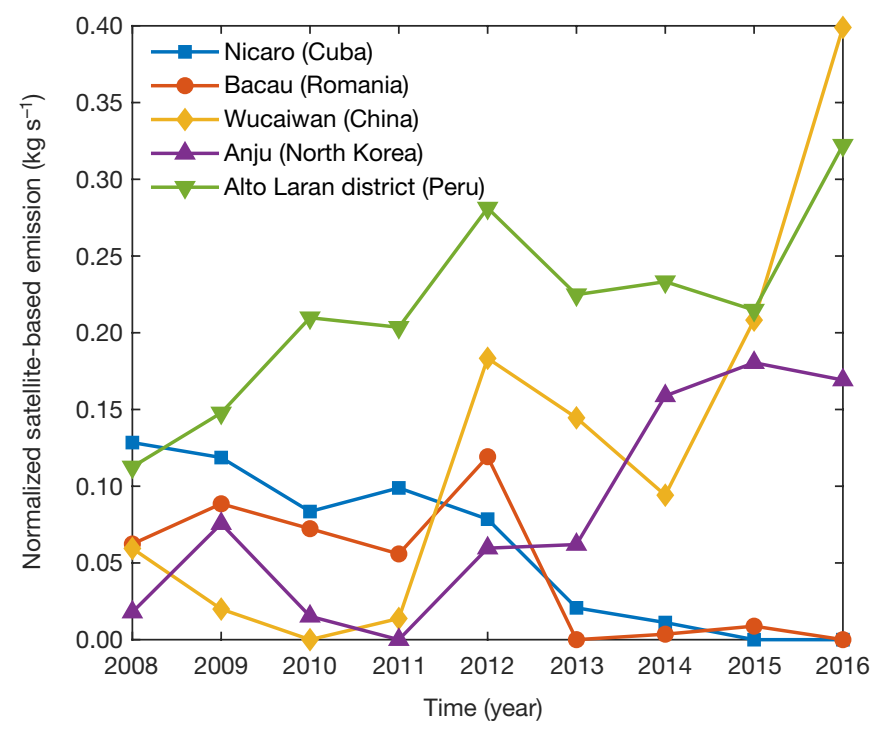

Fig. 4 | Examples of satellite-based ammonia emission trends. Time series of yearly averaged emission fluxes (in kilograms per second) over five industrial and agricultural point sources. The Nicaro, Bacau, Wucaiwan and Alto Laran district hotspots are discussed in the text; Anju illustrates the increase of fertilizer production in North Korea.
100:1, respectively. The coloured symbols are for selected sites. Fluxes are calculated assuming a baseline $\mathrm{NH}_{3}$ lifetime of $12 \mathrm{~h}$ (Methods); the error bars correspond to upper- and lower-bound flux estimates based on a lifetime of $1 \mathrm{~h}$ and $48 \mathrm{~h}$, respectively. Biomass-burning regions are omitted from this comparison because EDGAR does not include emissions from fires.

These examples show that IASI is capable of tracking the time evolution of relatively small emitters.

We have presented a detailed inventory of $\mathrm{NH}_{3}$ hotspots using almost a decade of satellite measurements. Most hotspots are associated with either high-density animal farming or industrial fertilizer production. The prolonged measurement period made it possible to reveal all sources with a sustained emission history, including those that are either too weak or too small to be identified on shorter timescales. Satellite flux estimates for larger source regions agree with emission inventories within a factor of three, in contrast to strongly localized point sources, over which extremely large flux differences are found, irrespective of their origin. In addition, two-thirds of all the hotspots apparently do not have a corresponding local maximum in the EDGAR inventory. Our results suggest that it is necessary to revisit the input data used for traditional bottom-up $\mathrm{NH}_{3}$ inventories and that space measurements can make an important contribution to the monitoring of ammonia emissions.

\section{Online content}

Any methods, additional references, Nature Research reporting summaries, source data, statements of data availability and associated accession codes are available at https://doi.org/10.1038/s41586-018-0747-1.

Received: 6 February 2018; Accepted: 11 October 2018;

1. Lelieveld, J., Evans, J. S., Fnais, M., Giannadaki, D. \& Pozzer, A. The contribution of outdoor air pollution sources to premature mortality on a global scale. Nature 525, 367-371 (2015).

2. Bauer, S. E., Tsigaridis, K. \& Miller, R. Significant atmospheric aerosol pollution caused by world food cultivation. Geophys. Res. Lett. 43, 5394-5400 (2016).

3. Galloway, J. et al. The nitrogen cascade. Bioscience 53, 341-356 (2003).

4. Bobbink, R. et al. Global assessment of nitrogen deposition effects on terrestrial plant diversity: a synthesis. Ecol. Appl. 20, 30-59 (2010).

5. Paerl, H. W., Gardner, W. S., McCarthy, M. J., Peierls, B. L. \& Wilhelm, S. W. Algal blooms: noteworthy nitrogen. Science 346, 175 (2014). 
6. Shindell, D. T. et al. Improved attribution of climate forcing to emissions. Science 326, 716-718 (2009).

7. Sutton, M. A. et al. Towards a climate-dependent paradigm of ammonia emission and deposition. Phil. Trans. R. Soc. B 368, 20130166 (2013).

8. Reis, S., Pinder, R. W., Zhang, M., Lijie, G. \& Sutton, M. A. Reactive nitrogen in atmospheric emission inventories. Atmos. Chem. Phys. 9, 7657-7677 (2009).

9. Behera, S., Sharma, M., Aneja, V. \& Balasubramanian, R. Ammonia in the atmosphere: a review on emission sources, atmospheric chemistry and deposition on terrestrial bodies. Environ. Sci. Pollut. Res. Int. 20, 8092-8131 (2013).

10. Emission Database for Global Atmospheric Research (EDGAR), release version 4.3.1 http://edgar.jrc.ec.europa.eu/overview.php?v=431 (2016)

11. Huang, X. et al. A high-resolution ammonia emission inventory in China. Glob. Biogeochem. Cycles 26, GB1030 (2012).

12. Meng, W. et al. Improvement of a global high-resolution ammonia emission inventory for combustion and industrial sources with new data from the residential and transportation sectors. Environ. Sci. Technol. 51, 2821-2829 (2017).

13. Clarisse, L., Clerbaux, C., Dentener, F., Hurtmans, D. \& Coheur, P.-F. Global ammonia distribution derived from infrared satellite observations. Nat. Geosci. 2, 479-483 (2009).

14. Shephard, M. W. et al. TES ammonia retrieval strategy and global observations of the spatial and seasonal variability of ammonia. Atmos. Chem. Phys. 11, 10743-10763 (2011).

15. Van Damme, M. et al. Global distributions, time series and error characterization of atmospheric ammonia $\left(\mathrm{NH}_{3}\right)$ from IASI satellite observations. Atmos. Chem. Phys. 14, 2905-2922 (2014).

16. Shephard, M. W. \& Cady-Pereira, K. E. Cross-track infrared sounder (CrIS) satellite observations of tropospheric ammonia. Atmos. Meas. Tech. $\mathbf{8}$ 1323-1336 (2015)

17. Warner, J. X. et al. Increased atmospheric ammonia over the world's major agricultural areas detected from space. Geophys. Res. Lett. 44, 2875-2884 (2017).

18. Streets, D. G. et al. Emissions estimation from satellite retrievals: a review of current capability. Atmos. Environ. 77, 1011-1042 (2013).

19. Zhu, L. et al. Constraining U.S. ammonia emissions using TES remote sensing observations and the GEOS-Chem adjoint model. J. Geophys. Res. Atmos. 118, 3355-3368 (2013).

20. Van Damme, M. et al. Evaluating 4 years of atmospheric ammonia $\left(\mathrm{NH}_{3}\right)$ over Europe using IASI satellite observations and LOTOS-EUROS model results. J. Geophys. Res. Atmos. 119, 9549-9566 (2014).

21. Whitburn, S. et al. A flexible and robust neural network IASI-NH $\mathrm{NH}_{3}$ retrieval algorithm. J. Geophys. Res. Atmos. 121, 6581-6599 (2016).

22. IFDC. Worldwide Ammonia Capacity Listing by Plant. Report No. IFDC-FSR-10 (IFDC, 2016).

23. Worldwide Syngas Database www.globalsyngas.org (2018).
24. Yasar, S., Orhan, H. \& Erensayin, C. Examining the nutritional and production characteristics of egg-farms in Basmakci County in Turkey. Worlds Poult. Sci. J. 59, 249-259 (2003).

25. Theobald, M. R. et al. Ammonia emissions from a Cape fur seal colony, Cape Cross, Namibia. Geophys. Res. Lett. 33, L03812 (2006).

26. Riddick, S. et al. High temporal resolution modelling of environmentallydependent seabird ammonia emissions: description and testing of the guano model. Atmos. Environ. 161, 48-60 (2017).

27. Uematsu, M. et al. Enhancement of primary productivity in the western North Pacific caused by the eruption of the Miyake-jima Volcano. Geophys. Res. Lett. 31, L06106 (2004).

Acknowledgements IASI is a joint mission of EUMETSAT (European Organisation for the Exploitation of Meteorological Satellites) and the Centre National d'Etudes Spatiales (CNES, France). The research in Belgium was funded by F.R.S.-FNRS and the Belgian State Federal Office for Scientific, Technical and Cultural Affairs (Prodex arrangement IASI.FLOW). L.C. is a Research Associate (Chercheur Qualifié) with the Belgian F.R.S.-FNRS. C.C. is grateful to CNES for scientific collaboration and financial support. We thank M. Zondlo for discussions and R. Astoreca for assistance with the identification of certain hotspots. We gratefully acknowledge the Nederlandse Organisatie voor toegepast-natuurwetenschappelijk onderzoek (TNO) for the LOTOSEUROS data used in the uncertainty analysis presented in the Supplementary Information.

Reviewer information Nature thanks F. Boersma and the other anonymous reviewer(s) for their contribution to the peer review of this work.

Author contributions M.V.D. and L.C. obtained the first hyperresolved maps of $\mathrm{NH}_{3}$ and performed the identification, classification and quantification of the sources, wrote the manuscript and prepared the figures. L.C., M.V.D., S.W. and J.H.-L. were responsible for the development of the retrieval algorithm and the processing of the IASI $\mathrm{NH}_{3}$ dataset. D.H. was responsible for the development of the forward model. C.C. and P.-F.C. contributed to the text and interpretation of the results and supervised the research.

Competing interests The authors declare no competing interests.

Additional information

Extended data is available for this paper at https://doi.org/10.1038/s41586018-0747-1.

Supplementary information is available for this paper at https://doi.org/ 10.1038/s41586-018-0747-1.

Reprints and permissions information is available at http://www.nature.com/ reprints.

Correspondence and requests for materials should be addressed to M.V.D. or L.C. Publisher's note: Springer Nature remains neutral with regard to jurisdictional claims in published maps and institutional affiliations. 


\section{METHODS}

The IASI instrument and $\mathrm{NH}_{3}$ dataset. IASI is a passive remote-sensing instrument that operates in downward viewing geometry to measure the infrared radiation emitted by Earth and its atmosphere in the $645-2,760 \mathrm{~cm}^{-1}$ spectral range. The data used in this study are derived from the IASI instrument onboard the Metop-A platform, which was launched in 2006 in a Sun-synchronous orbit with a mean local solar overpass time of 9:30 a.m. and 9:30 p.m. ${ }^{28}$. IASI has an elliptical footprint on the ground, ranging from $12 \times 12 \mathrm{~km}^{2}$ at nadir, up to $20 \times 39 \mathrm{~km}^{2}$ at its outermost viewing angle of $48^{\circ}$. Only measurements from the morning orbit have been used here, as IASI is generally more sensitive at this time to the atmospheric boundary layer, owing to more favourable thermal condition $\mathrm{s}^{29}$. The impact of the IASI overpass time on the derived fluxes was evaluated using a regional model and found to be of the order of $4 \% \pm 8 \%$ (provided that the diurnal variability is represented realistically in the model; see the uncertainty analyses in Supplementary Information, Supplementary Figs. 2, 4 and Supplementary Table 2).

This work relies on the ANNI-NH $\mathrm{N}_{3}$-v2.1R-I retrieval product and associated 2008-2016 dataset, which is described in full in ref. ${ }^{30}$. The retrieval algorithm is based on the calculation of a hyperspectral range index and its conversion to a $\mathrm{NH}_{3}$ column (in molecules per square centimetre) via an artificial neural network ${ }^{21}$. By exploiting a broad spectral range, full advantage is taken of the hyperspectral characteristics of IASI ${ }^{15,31}$. This method provides a full uncertainty budget but, in contrast to constrained approaches, no information on the vertical sensitivity of each measurement (averaging kernels). To be able to properly assess interannual variability and trends, the retrieval relies on the ERA-Interim reanalysis ${ }^{32}$ for its meteorological input data (temperature, pressure and water vapour profiles). Information on cloud coverage is provided for each IASI observation within the IASI level 2 product that is disseminated by EUMETSAT in near-real time ${ }^{33}$. Only measurements with a cloud fraction below $10 \%$ are retained. We note that until 3 March 2010, cloud fractions were not provided for all observations, resulting in reduced data availability and noisier distributions before this date (this is noticeable, for example, in Extended Data Fig. 4, especially for Torreón, where the distribution is more homogeneous after 2010). As no reliable variable global $\mathrm{NH}_{3}$ vertical profiles can be obtained from measurements and as the choice was made to keep the analyses free from model input, a fixed vertical profile was used for the retrieval. Although validation ${ }^{34,35}$ and cross-comparison ${ }^{29}$ studies have already excluded the existence of substantial biases in the IASI $\mathrm{NH}_{3}$ products, in the Supplementary Information we explicitly show that the choice of vertical profile cannot realistically affect the conclusions of this study (see the uncertainty analyses and Supplementary Fig. 4). Differences between columns derived with a fixed vertical profile (baseline) and columns derived using variable modelled profiles are of the order of $2 \% \pm 24 \%$ on a global scale, but may be substantially larger for individual locations linked to regional differences in meteorological mixing and recirculation.

Apart from the $\mathrm{NH}_{3}$ measurements provided by IASI, three other $\mathrm{NH}_{3}$ satellite products exist, from the instruments TES ${ }^{14}$, AIRS ${ }^{36}$ and $\mathrm{CrIS}^{16}$. The overall methodology applied in this study could readily be applied to the last two datasets. The TES data however, would be less suitable because the spatial coverage of TES is too limited. It should also be noted that the $\mathrm{NH}_{3}$ datasets from the other instruments are based on retrieval algorithms that use a priori information. To obtain unbiased flux estimates, more sophisticated flux calculations (for example, full formal inversion using atmospheric models) would be required. If these datasets would be taken at face value, we speculate that the inventory of hotspots and source regions would not be substantially different. However, the resulting fluxes would probably be even larger than those reported here, as preliminary intercomparisons have shown that retrieved columns are typically higher, partly because all of these instruments make early-afternoon measurements.

The global nine-year IASI average. The most widely used methods for averaging scattered satellite data rely on interpolation or binning on a rectangular latitude-longitude grid with a cell size comparable to the spatial resolution of the instrument. For IASI this is typically $0.125^{\circ}, 0.25^{\circ}, 0.5^{\circ}$ or coarser. However, such approaches only take into account the location of the centre of the observation and not its spatial extent. Oversampling methods ${ }^{18}$ allow us to obtain averages at a much higher resolution and have already proven to be very successful in the study of $\mathrm{NO}_{2}, \mathrm{SO}_{2}, \mathrm{HCHO}$ and $\mathrm{CO}$ sources ${ }^{37-45}$. These approaches exploit the fact that the location, shape and orientation of the satellite footprint on the ground varies from one orbit to another, so that by sacrificing temporal information, additional information can be obtained on the spatial distribution. This is akin to tomographic reconstruction in which multiple two-dimensional measurements from different angles are used to obtain a single three-dimensional measurement. Here we have adopted an oversampling technique very similar to the one applied for the averaging of $\mathrm{NO}_{2}$ data from $\mathrm{OMI}^{37}$. A grid size of $0.01^{\circ} \times 0.01^{\circ}$ was chosen over the area ranging from $70^{\circ} \mathrm{S}$ to $70^{\circ} \mathrm{N}$. For each observation, the footprint on the ground was calculated for IASI ${ }^{46}$ and, for computational reasons, approximated as an ellipse on a rectangular latitude-longitude grid. All measurements that cover a given cell were included in the calculation of the cell-averaged value. To account for differences in the footprint size, the averaging was performed with a weight inversely proportional to the area of each footprint. In previous work on $\mathrm{NO}_{2}{ }^{37}$, the weight of each measurement, in addition to the area, includes another term that is related to the measurement error. Here such a term was not added because the dynamic range of both the $\mathrm{NH}_{3}$ column and its associated error is so large that weighing with either the relative or absolute error biases the average considerably ${ }^{15,21,30}$. However, obviously erroneous measurements were excluded with an outlier test: for each measurement, the mean and standard deviation of all measurements within a $1^{\circ} \times 1^{\circ}$ box were calculated, and the measurement was considered an outlier if it was more than 10 standard deviations from the average. In total, $0.014 \%$ of the measurements were excluded in this way. As an illustration of the method, an average of two days of IASI $\mathrm{NH}_{3}$ measurements is shown in Extended Data Fig. 2. Because of cloud cover and the varying satellite sensitivity, not all periods of the year are sampled equally. However, analysis with an alternative approach, in which each month is assigned the same weight (see the uncertainty analyses in the Supplementary Information and Supplementary Fig. 4), reveals that the effect on the global distribution is modest, with emission estimates $4 \% \pm 7 \%$ lower in the monthly based average.

The oversampling approach exploits all the spatial information contained within the measurement, without making any assumptions on, for example, the smoothness of the measured data. This is particularly useful for averaging measured data of a short-lived species such as $\mathrm{NH}_{3}$, which exhibits sharp gradients close to its sources. Extended Data Fig. 3 compares an oversampled average (right; $0.01^{\circ} \times 0.01^{\circ}$ ) with a more traditional binned average (left; $\left.0.25^{\circ} \times 0.25^{\circ}\right)$ for the Nile Delta and Valley using the entire nine-year dataset. The figure demonstrates the considerable increase achieved in spatial resolution. Of particular relevance to this study are the two point sources in the north of the Gulf of Suez (Ain Sukhna and Al-Adabiya), which can only be distinguished in the oversampled average. We note that no artificial smoothing was performed in any of the maps that are shown here and in the Supplementary Information; their smooth appearance is solely due to the applied methodology, the sensitivity of the $\mathrm{NH}_{3}$ algorithm and the availability of a large amount of data. For future work, one direction that could be envisaged is explicitly accounting for surface winds in the averaging. In certain cases, this could facilitate the isolation and identification of the hotpots in larger source regions ${ }^{45}$

Identification and attribution. The identification of hotspot locations and source regions was carried out manually. Although automated ways benefit from more consistency, no satisfactory set of criteria was found that could be applied globally or even per continent. This is particularly related to the fact that in certain areas, $\mathrm{NH}_{3}$ concentrations are much more variable or $\mathrm{NH}_{3}$ measurements are noisier. $\mathrm{NH}_{3}$ emitted by biomass burning can especially hamper the identification of hotspots over a large area, even on a nine-year average (for example, most of South America and western Africa). As the static EDGAR emission inventory does not include biomass-burning emissions, the choice was made to completely exclude large regions with frequent biomass-burning episodes, both for the analysis of the hotspots and the analysis of source regions. Such regions were selected on the basis of the MODIS fire product ${ }^{47}$; regions with more than $2 \times 10^{-2}$ fires per square kilometre for the entire period $2008-2016$ were excluded. An assessment of specific fire emission inventories using IASI-derived $\mathrm{NH}_{3}$ emissions can be found in earlier work ${ }^{48,49}$. For the manual identification of hotspots, local maxima were identified that exhibited a characteristic smoothness compatible with a single source or a cluster of closely located sources and with a magnitude clearly above background values. This led to hotspot identification of areas typically smaller than $50 \mathrm{~km}$. When the position of the maximum could not be clearly identified because it was spread over a large region, the area was classified as a source region instead of a hotspot. Because the above analysis was carried out on a best-effort basis, it necessarily involved some level of arbitrariness. In addition, numerous hotspots inevitably eluded identification, especially within larger source areas. The choice was also made not to use third-party sources (reported hotspots in the literature derived from in situ measurements or modelled data), which could bias the analysis. For instance, after it emerged that IASI is able to detect a complex of geothermal power plants in the United States, we could confirm the detection of other geothermal power plant locations, like the well-documented one in the Mount Amiata area in Italy ${ }^{50}$. Another example is the fertilizer plant in Campana, close to Buenos Aires (Argentina), which appears on lists of $\mathrm{NH}_{3}$ producers, and over which a small hotspot was indeed discerned a posteriori. However, its magnitude is not much larger than the hundreds of other local maxima in the region. Such hotspots that could not be identified unambiguously from the satellite data alone have therefore not been included.

After the list of hotspots and source regions was established, they were further analysed to ascertain the dominant origin of the observed $\mathrm{NH}_{3}$. First, visible imagery was studied with Google Earth using both its image overlay and historical 
imagery features. Agricultural activities (especially crop fields) exist in almost all populated places. Very frequently, where these activities looked no different in or outside the hotspot area (that is, showed no apparent signs of high-intensity animal farming), industrial sites could be spotted. So just by studying the imagery an educated guess could be made on whether industrial activity was involved or not. The high spatial resolution of the distribution proved to be invaluable here, as in many cases it allowed to pinpoint the location of the source within a few kilometres. This was less the case for sites on or near the coast, where owing to stronger winds the location of the maximum $\mathrm{NH}_{3}$ column was sometimes observed up to $10 \mathrm{~km}$ away from its likely source (for example, the Nicaro mine in Cuba).

The presence of fertilizer production plants could be easily confirmed in most of the industrial cases by using a variety of publicly available inventories, in particular the IFDC Worldwide Ammonia Capacity Listing by Plant ${ }^{22}$, the Worldwide Syngas Database $^{23}$ and others (www.ammoniaindustry.com, www.fert.cn). Identification of the industry type was most difficult in China, where the industry is still rapidly developing and many fertilizer plants have yet to be included in these inventories. In addition, as already mentioned in the main text, fertilizer plants are often found close to other coal-related chemical industries that also emit ammonia. As soon as the presence of a fertilizer plant could be confirmed, the source was tagged as 'fertilizer industry', even when other industrial sources were clearly present. When this was not the case, it was tagged as 'other industry'; this category included mainly chemical or steel industries ${ }^{51,52}$, but also the aforementioned geothermal power plant and two nickel-cobalt mines. Two hotspots were found to be associated with fires in coalmines (near Abakan, Russia and near Jharia, India) and these were classified under 'other industry' as well.

For a handful of hotspots (6) -in particular, those located near the large cities of Mexico City (Mexico), Bamako (Mali) and Niamey (Niger)—no obvious point sources could be identified. Most of the increases observed over other megacities were found to be too diluted or mixed with sources from outside to be classified as hotspots (for example, Sao Paulo in Brazil and Shanghai in China).

In addition to the identification and source attribution, a name was assigned to each hotspot and region. This was usually the name of the nearest medium-size city or for the larger areas the name of the region, province or geographical areawhichever was deemed most appropriate. For the hotspots, the approximate coordinates of their centres were established, as well as the size of an imaginary box around them, outside which the observed concentrations fall back to background values. These data were then used for the calculation of the flux data, as outlined below. The source regions were all approximated as rectangles on the latitudelongitude grid, the coordinates of which were also recorded.

Emission flux calculations. Following previous studies on $\mathrm{NH}_{3}$ emissions from fires ${ }^{49}$ and $\mathrm{SO}_{2}$ sources ${ }^{53}$, emission fluxes $(E)$ were calculated from the IASI $\mathrm{NH}_{3}$ distributions with a box model that assumes stationarity and constant first-order loss terms, that is, $E=M / \tau$. Here, $M$ is the total mass contained within the assumed box, that is, the sum of the measured masses in each $0.01^{\circ} \times 0.01^{\circ}$ grid cell. These are obtained directly from their surface area and the measured satellite average $\mathrm{NH}_{3}$ column (in molecules per square centimetre). The effective lifetime or residence time $\tau$ of $\mathrm{NH}_{3}$ within a given box is defined for such a model as ${ }^{54}$

$$
\frac{1}{\tau}=\frac{1}{\tau_{\text {out }}}+\frac{1}{\tau_{\text {chem }}}+\frac{1}{\tau_{\text {dep }}}
$$

with $\tau_{\text {out }}, \tau_{\text {chem }}$ and $\tau_{\text {dep }}$ the lifetimes associated with export, chemical loss and deposition, respectively. Disregarding transport out of the box, the lifetime is believed to be of the order of a few hours to a few days (see Supplementary Table 1). In this study, the effective lifetime was set to $12 \mathrm{~h}$ on the basis of the limited data available in the literature. Using a set lifetime is a limitation of the method, as deposition rates and chemical losses are highly variable. The lifetime of $\mathrm{NH}_{3}$ depends on the presence of other pollutants, meteorological variables (water vapour, clouds and temperature), winds (atmospheric mixing and recirculation) and the $\mathrm{NH}_{3}$ column itself. In addition, the bidirectional nature of $\mathrm{NH}_{3}$ surface-atmosphere fluxes can have a large and highly variable contribution ${ }^{55}$. For many of the hotspots, there can be substantial transport out of the box, in which case the effective lifetime is smaller than $12 \mathrm{~h}$. Given the average size of the boxes, the IASI flux estimates derived in this way are more likely to be underestimated than overestimated. For specific remote sites, however, $12 \mathrm{~h}$ could be too short. Therefore, to account for these uncertainties, fluxes were also calculated using lifetimes of $1 \mathrm{~h}$ and $48 \mathrm{~h}$ to provide conservative upper- and lower-bound flux estimates; the corresponding values are shown as error bars in Fig. 3. In addition, it is worth noting that analyses of temporal variability in emissions mostly do not depend on $\mathrm{NH}_{3}$ retrieval or inverse model assumptions and hence are better constrained than the absolute fluxes. This is illustrated, for instance, in Fig. 4. Although other, more sophisticated methods are available ${ }^{56}$, which can also estimate the effective lifetime from the data, an advantage of the box model is that it does not rely on external wind data.
More importantly, it is also applicable to both clusters of point sources and source areas, for which most of the other methods cannot be used.

Emissions for the larger source areas were calculated directly according to $E=M / \tau$. For the hotspots, a background column was first subtracted from the $\mathrm{NH}_{3}$ columns, so as to include only the emission fluxes of the point sources that are responsible for the hotspots. The background column was estimated as the 10th percentile of all the $0.01^{\circ} \times 0.01^{\circ}$ average columns in the box around the hotspot. Other choices, such as the 5th or 15th percentile, are equally defendable. In the Supplementary Information (see the uncertainty analyses and Supplementary Figs. 3 and 4), we show that these alternative choices alter the fluxes by $-18 \% \pm 7 \%$ ( 5 th percentile) and $14 \% \pm 5 \%$ (15th percentile). The background correction is illustrated in the Supplementary Information for all the hotspots mentioned in the main text.

Emission fluxes were also calculated from the EDGAR v4.3.1 inventory ${ }^{10,57}$ to compare with our satellite-based emission estimates. For 2010, the inventory is provided at a resolution of $0.1^{\circ} \times 0.1^{\circ}$ and separated into 17 sectors. Because the inventory provides emissions, only minor manipulation of the data was needed. The inventory was first regridded to the $0.01^{\circ} \times 0.01^{\circ}$ resolution of the IASI averages. For the source regions, EDGAR fluxes were then summed over the entire box and over all sectors. For the hotspots, only the fluxes of the cells that contain the assumed dominant point sources were considered because the satellite fluxes were calculated to represent only these. Those cells were determined as the largest 10th percentile cells of all the $0.01^{\circ} \times 0.01^{\circ}$ averaged observed columns in the box. As can be seen in the six-panel figures in the Supplementary Information (pages 2-29; the cells considered are located inside the black contour), this gives a reasonable approximation of what cells should be taken into account. Then, depending on the assigned source category, emissions found in the selected grid cells were added to obtain an estimated emission total of the dominant point sources in the box. We note that emissions from industry included the following sectors: power industry, oil refineries, transformation industry, combustion for manufacturing, process emissions during production and application, and solid waste and wastewater.

For several reasons, EDGAR may underestimate fluxes over hotspots even more than shown in Fig. 3. First, as explained above, the average effective lifetime is probably smaller than the $12 \mathrm{~h}$ used, leading to an underestimation of the IASIderived flux (Supplementary Information). Second, IASI $\mathrm{NH}_{3}$ measurements are more likely to underestimate $\mathrm{NH}_{3}$ columns than to overestimate them because, depending on the thermal contrast, IASI (as any other infrared instrument) can be blind to the lower layer of the atmosphere, where $\mathrm{NH}_{3}$ is emitted. Early validation efforts have also indicated that the IASI NH $\mathrm{N}_{3}$ measurements tend to underestimate ambient $\mathrm{NH}_{3}$ concentrations, even when there is sufficient sensitivity ${ }^{34,35}$. Third, in the methodology presented, background emissions are not removed for the flux calculations from EDGAR. For instance, for the flux estimate over a feedlot, the total flux still includes the contribution of other agricultural activities within the cells considered.

\section{Data availability}

The $\mathrm{NH}_{3}$ map is available in NetCDF and KMZ formats. The latter file includes the identified hotspots and source regions and is provided in the Supplementary Information. The supplement also includes the 28 hotspot illustrations. The NetCDF file of the $\mathrm{NH}_{3}$ map and the reanalysed IASI NH $\mathrm{N}_{3}$ dataset (ANNI$\mathrm{NH}_{3}$-v2.1R-I) described in Methods are available from the PANGAEA repository (https://doi.org/10.1594/PANGAEA.894736); more recent versions of IASI $\mathrm{NH}_{3}$ datasets are available from the AERIS data infrastructure (http://iasi.aerisdata.fr). The $\mathrm{NH}_{3}$ product from IASI will also be operationally distributed by EUMETCast, under the auspices of the EUMETSAT Atmospheric Monitoring Satellite Application Facility (AC-SAF; http://ac-saf.eumetsat.int).

28. Clerbaux, C. et al. Monitoring of atmospheric composition using the thermal infrared IASI/MetOp sounder. Atmos. Chem. Phys. 9, 6041-6054 (2009).

29. Clarisse, L. et al. Satellite monitoring of ammonia: a case study of the San Joaquin Valley. J. Geophys. Res. 115, D13302 (2010)

30. Van Damme, M. et al. Version 2 of the IASI $\mathrm{NH}_{3}$ neural network retrieval algorithm: near-real-time and reanalysed datasets. Atmos. Meas. Tech. 10 4905-4914 (2017)

31. Walker, J. C., Dudhia, A. \& Carboni, E. An effective method for the detection of trace species demonstrated using the MetOp Infrared Atmospheric Sounding Interferometer. Atmos. Meas. Tech. 4, 1567-1580 (2011)

32. Dee, D. P. et al. The ERA-Interim reanalysis: configuration and performance of the data assimilation system. Q. J. R. Meteorol. Soc. 137, 553-597 (2011).

33. August, T. et al. IASI on Metop-A: Operational Level 2 retrievals after five years in orbit. J. Quant. Spectrosc. Radiat. Transf. 113, 1340-1371 (2012)

34. Van Damme, M. et al. Towards validation of ammonia $\left(\mathrm{NH}_{3}\right)$ measurements from the IASI satellite. Atmos. Meas. Tech. 8, 1575-1591 (2015).

35. Dammers, E. et al. An evaluation of IASI-NH $\mathrm{NH}_{3}$ with ground-based Fourier transform infrared spectroscopy measurements. Atmos. Chem. Phys. 16, 10351-10368 (2016). 
36. Warner, J. X., Wei, Z., Strow, L. L., Dickerson, R. R. \& Nowak, J. B. The global tropospheric ammonia distribution as seen in the 13-year AIRS measurement record. Atmos. Chem. Phys. 16, 5467-5479 (2016).

37. Wenig, M. O. et al. Validation of OMI tropospheric $\mathrm{NO}_{2}$ column densities using direct-Sun mode Brewer measurements at NASA Goddard Space Flight Center. J. Geophys. Res. 113, D16S45 (2008).

38. Fioletov, V. E., McLinden, C. A., Krotkov, N., Moran, M. D. \& Yang, K. Estimation of $\mathrm{SO}_{2}$ emissions using OMI retrievals. Geophys. Res. Lett. 38, L21811 (2011).

39. Lu, Z., Streets, D. G., de Foy, B. \& Krotkov, N. A. Ozone Monitoring Instrument observations of interannual increases in $\mathrm{SO}_{2}$ emissions from Indian coal-fired power plants during 2005-2012. Environ. Sci. Technol. 47, 13993-14000 (2013).

40. Pommier, M., McLinden, C. A. \& Deeter, M. Relative changes in CO emissions over megacities based on observations from space. Geophys. Res. Lett. 40 , 3766-3771 (2013).

41. Zhu, L. et al. Anthropogenic emissions of highly reactive volatile organic compounds in eastern Texas inferred from oversampling of satellite (OMI) measurements of HCHO columns. Environ. Res. Lett. 9, 114004 (2014).

42. de Foy, B., Lu, Z., Streets, D. G., Lamsal, L. N. \& Duncan, B. N. Estimates of power plant $\mathrm{NO}_{x}$ emissions and lifetimes from $\mathrm{OMI} \mathrm{NO}_{2}$ satellite retrievals. Atmos. Environ. 116, 1-11 (2015).

43. Fioletov, V. E., McLinden, C. A., Krotkov, N. \& Li, C. Lifetimes and emissions of $\mathrm{SO}_{2}$ from point sources estimated from OMI. Geophys. Res. Lett. 42, 1969-1976 (2015).

44. Krotkov, N. A. et al. Aura OMI observations of regional $\mathrm{SO}_{2}$ and $\mathrm{NO}_{2}$ pollution changes from 2005 to 2015. Atmos. Chem. Phys. 16, 4605-4629 (2016).

45. McLinden, C. A. et al. Space-based detection of missing sulfur dioxide sources of global air pollution. Nat. Geosci. 9, 496-500 (2016)

46. Marsouin, A. \& Brunel, P. AAPP Documentation, Annex of Scientific Description, AAPP Navigation. Report No. NWPSAF-MF-UD-005 (EUMETSAT, 2011).
47. Giglio, L., Schroeder, W. \& Justice, C. O. The collection 6 MODIS active fire detection algorithm and fire products. Remote Sens. Environ. 178, 31-41 (2016).

48. Whitburn, S. et al. Ammonia emissions in tropical biomass burning regions: Comparison between satellite-derived emissions and bottom-up fire inventories. Atmos. Environ. 121, 42-54 (2015).

49. Whitburn, S. et al. Doubling of annual ammonia emissions from the peat fires in Indonesia during the 2015 El Niño. Geophys. Res. Lett. 43, 11007-11014 (2016).

50. Bravi, M. \& Basosi, R. Environmental impact of electricity from selected geothermal power plants in Italy. J. Clean. Prod. 66, 301-308 (2014).

51. Wang, S. et al. Atmospheric ammonia and its impacts on regional air quality over the megacity of Shanghai, China. Sci. Rep. 5, 15842 (2015).

52. Roe, S. M. et al. Estimating Ammonia Emissions from Anthropogenic Nonagricultural Sources. Draft Final Report (US Environmental Protection Agency, 2004).

53. Theys, N. et al. Volcanic $\mathrm{SO}_{2}$ fluxes derived from satellite data: a survey using OMI, GOME-2, IASI and MODIS. Atmos. Chem. Phys. 13, 5945-5968 (2013).

54. Jacob, D. J. Introduction to Atmospheric Chemistry (Princeton Univ. Press, Princeton, 1999)

55. Zhu, L. et al. Global evaluation of ammonia bidirectional exchange and livestock diurnal variation schemes. Atmos. Chem. Phys. 15, 12823-12843 (2015).

56. de Foy, B., Wilkins, J. L., Lu, Z., Streets, D. G. \& Duncan, B. N. Model evaluation of methods for estimating surface emissions and chemical lifetimes from satellite data. Atmos. Environ. 98, 66-77 (2014).

57. Crippa, M. et al. Forty years of improvements in European air quality: regional policy-industry interactions with global impacts. Atmos. Chem. Phys. 16, 3825-3841 (2016). 


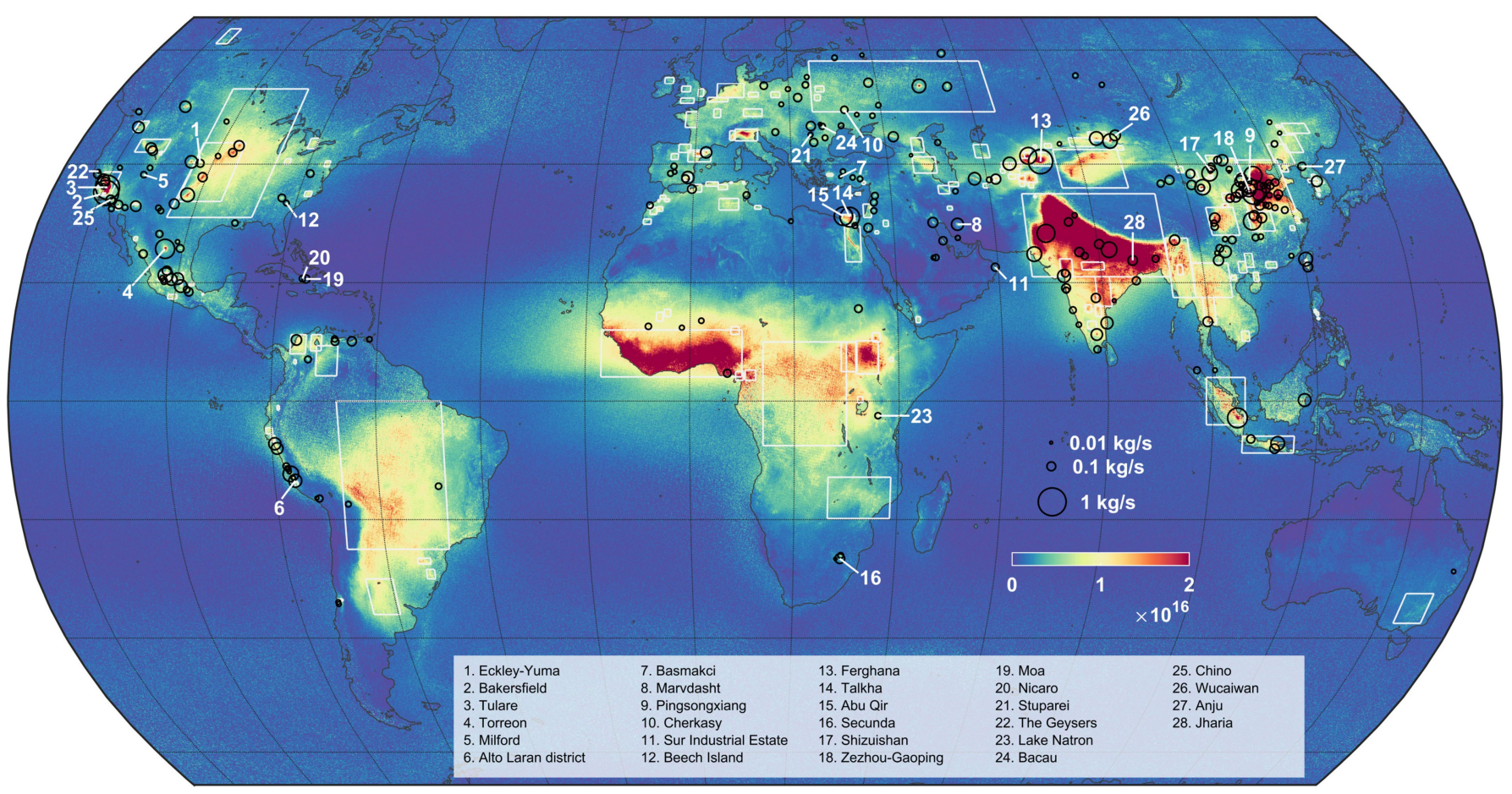

Extended Data Fig. 1 | Source areas and hotspot locations. Global nine-year $\mathrm{NH}_{3}$ average (in molecules per square centimetre) with identified hotspots, their associated flux estimates (black circles), and source areas (white rectangles). In total 248 hotspots and 178 source areas are indicated (see Supplementary Information for details). The locations and names of the hotspots discussed in the main text are also provided. The largest average $\mathrm{NH}_{3}$ column is found over the Indus Valley (Pakistan) with a value of $1.1 \times 10^{17}$ molecules $\mathrm{cm}^{-2}$. 


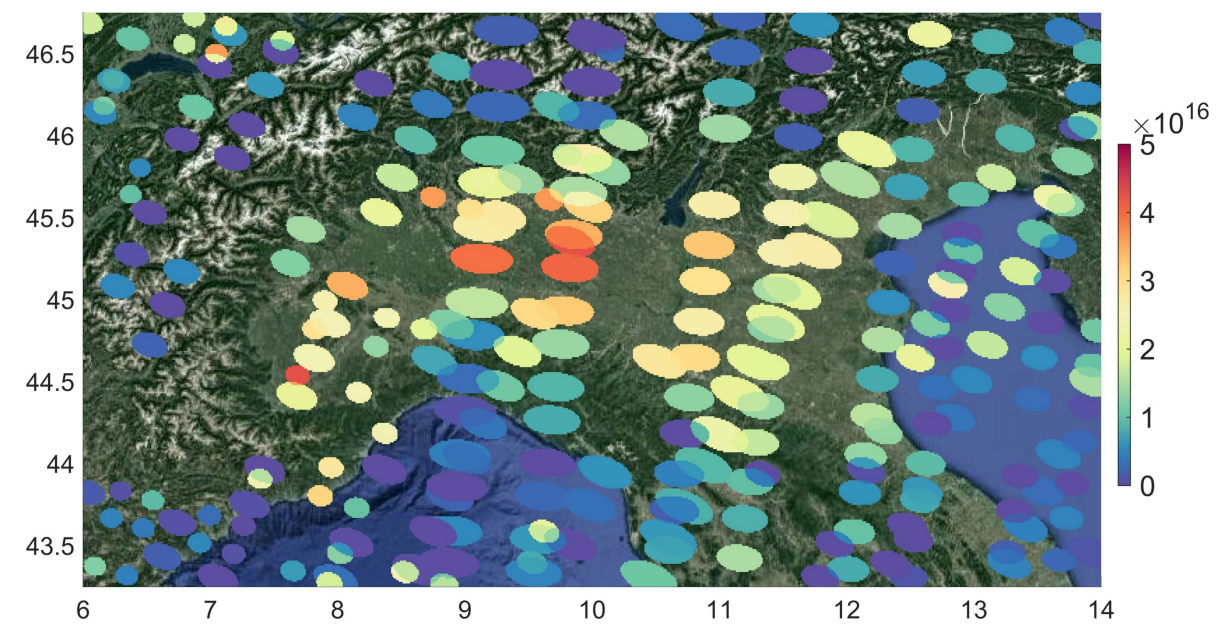

Extended Data Fig. 2 Satellite footprint averaging. Example of two days (20 and 21 July 2016) of IASI/Metop-A morning $\mathrm{NH}_{3}$ observations (in molecules per square centimetre) over the Po Valley. The elliptical footprints of IASI are averaged on a $0.01^{\circ} \times 0.01^{\circ}$ high-resolution grid and weighted by the inverse of their footprint area. Map data from Google Earth and Landsat/Copernicus. 

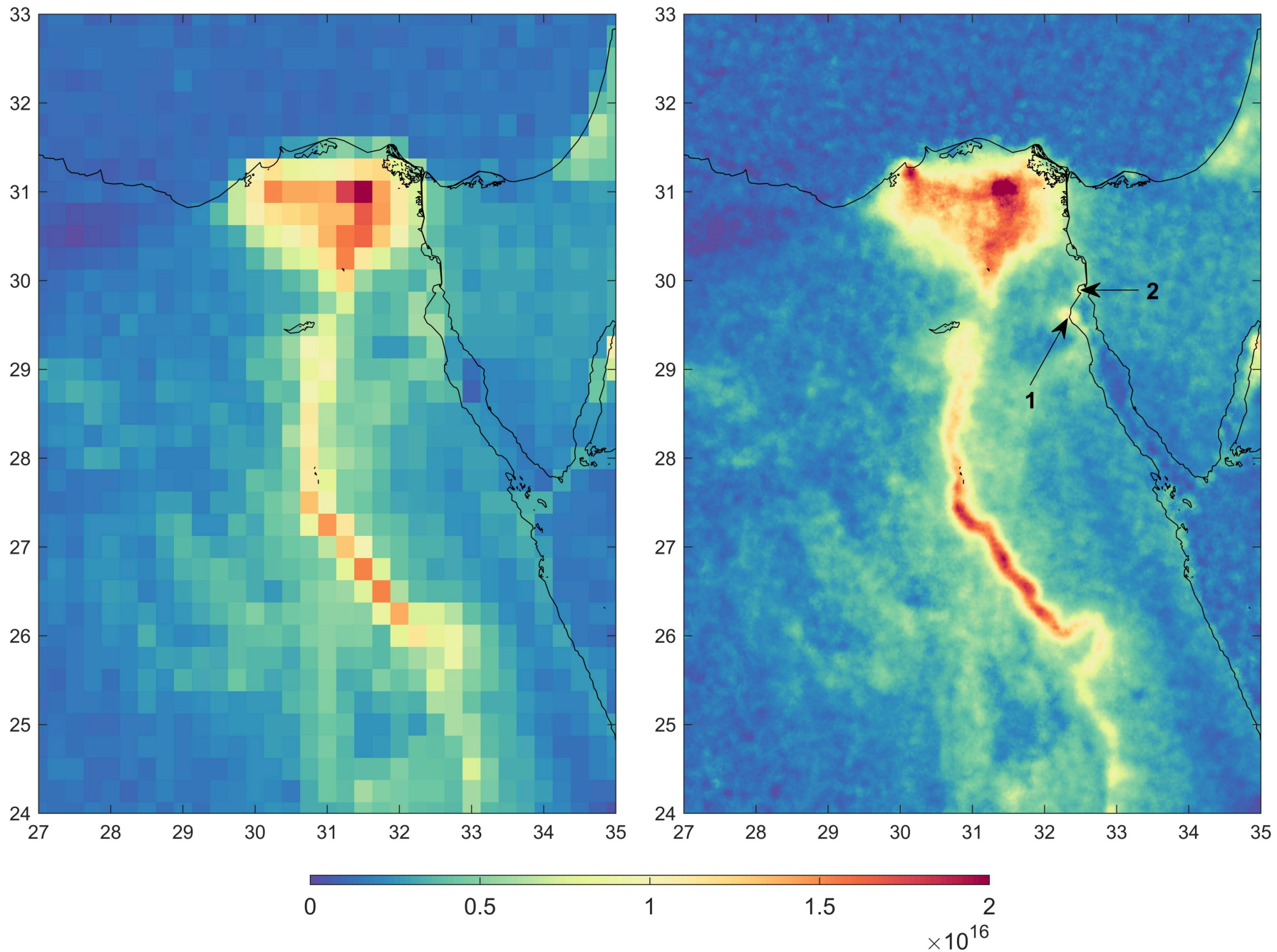

Extended Data Fig. 3 Binned and oversampled averages over the Nile Delta and Valley. The right panel demonstrates the oversampled average (on a $0.01^{\circ} \times 0.01^{\circ}$ grid; maximum value of $3.1 \times 10^{16}$ molecules $\mathrm{cm}^{-2}$ ); the left panel shows the traditional binned average (on a $0.25^{\circ} \times 0.25^{\circ}$ grid; maximum value of $2.2 \times 10^{16}$ molecules $\mathrm{cm}^{-2}$ ) of IASI/Metop-A morning

$\mathrm{NH}_{3}$ observations from 2008 to 2016 (in molecules per square centimetre; $12 \times 12 \mathrm{~km}^{2}$ at nadir); see Methods for details. The increase in resolution allows the identification of two point sources in the north of the Gulf of Suez, Ain Sukhna (1) and Al-Adabiya (2), which cannot be singled out with a more traditional gridding approach. 


\section{RESEARCH LETTER}
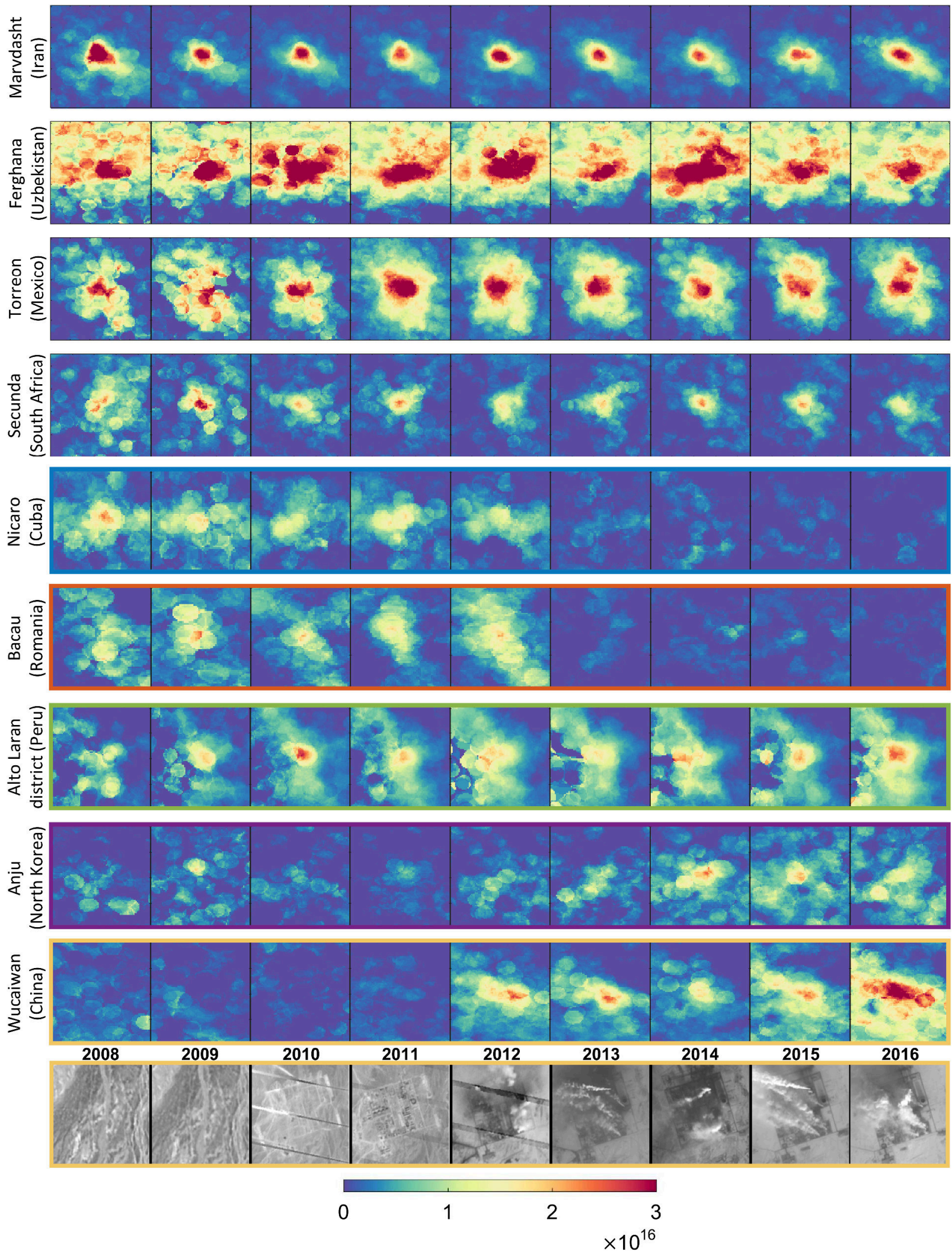

Extended Data Fig. $4 \mid$ IASI $\mathrm{NH}_{3}$ yearly distributions. Yearly $\mathrm{NH}_{3}$ maps (in molecules per square centimetre) over several hotspots: (from top to bottom) Marvdasht (Iran), Ferghana (Uzbekistan), Torreón (Mexico), Secunda (South Africa), Nicaro (Cuba; blue in Fig. 4), Bacau (Romania; orange in Fig. 4), Alto Laran district (Peru; green in Fig. 4), Anju (North Korea; purple in Fig. 4) and Wucaiwan (China; yellow in Fig. 4).
The 2008 and 2009 distributions are noisier owing to reduced data availability (see Methods). The Wucaiwan industrial point source can be seen to appear in Landsat-5 (2008-2009), -7 (2010-2012) and -8 (2013-2016) images (bottom panels). Map data from Google Earth and Landsat/Copernicus. 